\title{
Características químicas do solo e produção de biomassa de alface adubada com compostos orgânicos
}

\author{
Leandra B. de Oliveira ${ }^{1}$, Adriana M. A. Accioly ${ }^{2}$, Carlos L. R. dos Santos ${ }^{3}$, \\ Rilner A. Flores ${ }^{4} \&$ Flávia S. Barbosa ${ }^{5}$ \\ ${ }^{1}$ UFRPE, Recife, PE. E-mail: leandramaiorane@yahoo.com.br \\ ${ }^{2}$ Embrapa Mandioca e Fruticultura, Cruz das Almas, BA. E-mail: adriana.accioly@embrapa.br \\ ${ }^{3}$ FCAV/UNESP, Jaboticabal, SP. E-mail: caleufrrj@bol.com.br \\ ${ }^{4}$ Escola de Agronomia da UFG, Goiânia, GO. E-mail: rilner1@hotmail.com (Autor correspondente) \\ ${ }^{5}$ CCAAB/UFRB, Cruz das Almas, BA. E-mail: barbosasilva_f@yahoo.com.br
}

Palavras-chave:

disponibilidade de nutrientes fertilidade do solo

nitrogênio

\begin{abstract}
R E S U M O melhoram sobretudo as características químicas do solo e reduzem a acidez potencial.

\section{Chemical characteristics of the soil and biomass of lettuce fertilized with organic compounds}

Objetivou-se, neste trabalho, avaliar as alterações das características químicas do solo e a resposta produtiva da alface adubada com compostos orgânicos confeccionados artesanalmente a partir de resíduos e/ou matérias-primas. Os tratamentos foram distribuídos no delineamento de blocos ao acaso no esquema fatorial $5 \times 4$, sendo cinco tipos e quatro doses de compostos orgânicos, com quatro repetições, aplicados em plantas crescidas em vasos por 35 dias, sob condições de casa de vegetação. No solo, as variáveis avaliadas foram: teor de matéria orgânica, teores dos nutrientes $\mathrm{P}, \mathrm{K}^{+}, \mathrm{Na}^{+}, \mathrm{Ca}^{2+} \mathrm{e} \mathrm{Mg}^{2+}$, acidez potencial $\left(\mathrm{H}^{+}+\mathrm{Al}^{3+}\right)$, soma de bases (valor S), capacidade de troca de cátions (CTC), saturação por bases (V\%) e pH. Avaliou-se, nas plantas, a biomassa seca da parte aérea. A adição dos compostos orgânicos aumentou a produção de matéria seca da alface e o teor de matéria orgânica no solo. A elevação de doses dos compostos orgânicos por ocasião da adubação da alface favorece o aumento não apenas dos teores de fósforo e de sódio trocável no solo, mas também dos teores de cálcio e potássio, com o uso de alguns compostos. Os compostos 3 (Resíduos orgânicos doméstico, urbano e industrial) e 4 (Composto commercial - Greenworld)
Key words: nutrient availability soil fertility nitrogen

\begin{abstract}
A B S T R A C T
The objective of the present study was to evaluate changes in chemical characteristics of soil and yield response of lettuce fertilized with organic compounds from waste and/or raw materials. Treatments were arranged in a randomized block design in a $5 \times 4$ factorial scheme, with five types and four doses of organic compounds, with four replications, applied to plants grown in pots for 35 days under greenhouse conditions. In the soil, the evaluated variables were: organic matter content, nutrient content $-\mathrm{P} \mathrm{K}^{+}, \mathrm{Na}^{+}, \mathrm{Ca}^{2+}$ and $\mathrm{Mg}^{+2}$, potential acidity $\left(\mathrm{H}^{+}+\mathrm{Al}^{3+}\right)$, sum of bases (S value), cation exchange capacity (CEC), base saturation (V\%) and $\mathrm{pH}$. In plants, dry matter yield of shoot was assessed. The addition of organic compounds increased the dry matter yield of the lettuce and organic matter content in soil, favoring the increase of phosphorus and exchangeable sodium in soil, also, increase in calcium and potassium were observed, with use of some compounds. Compounds 3 (domestic, urban and industrial residues) and 4 (Commercial Composto - Greenworld), mainly, improve the chemical characteristics of soil and reduce potential acidity.
\end{abstract}

\section{INTRODUÇÃo}

A alface (Lactuca sativa L.) é a hortaliça folhosa mais cultivada e consumida no Brasil, cujos cultivos são realizados principalmente em pequenas áreas e por produtores familiares (Resende et al., 2007). Em seu cultivo é bastante comum uso de adubação orgânica como forma de suplementação nutricional às plantas. De forma geral, o uso de compostos à base de resíduos orgânicos em atividades agrícolas é uma alternativa interessante haja vista que proporciona aumento de produtividade e reduz o custo com fertilizantes (Kiehl, 1985), além de proporcionar a deposição segura desses materiais no ambiente (Figueiredo \& Tanamati, 2010; Montemurro et al., 2010).

Na maioria dos casos a adubação com compostos orgânicos no solo proporciona aumento do rendimento da alface (Galbiatti et al., 2007; Oliveira et al., 2009, 2010; Nazareno et al., 2010; Silva et al., 2011; Santana et al., 2012). Em alguns solos não se observa efeito da aplicação de compostos na produtividade (Roel et al., 2007), porém as plantas de alface podem ser beneficiadas pelo aumento do teor vitamínico das folhas e pelo menor acúmulo de 
nitrato comparado a plantas adubadas com adubo mineral (Silva et al., 2011) ou, mesmo, com o efeito supressivo de pragas ou doenças, como observado por Nazareno et al. (2010) estudando nematóides de galhas em alface.

A aplicação de compostos orgânicos no solo pode provocar alterações dos atributos químicos, físicos e biológicos (Abreu Júnior et al., 2002; Brito et al., 2005; Silva et al., 2008; Cunha et al., 2012) e ser viável para a melhoria da qualidade do solo; seus efeitos, contudo, devem ser monitorados (Abreu Júnior et al., 2002).

$\mathrm{Na}$ cultura da alface alguns trabalhos relatam a alteração das características químicas do solo com a aplicação de compostos orgânicos (Santos et al., 2001; Parizotto \& Pandolfo, 2009; Pimentel et al., 2009; Montemurro et al., 2010; Cardoso et al., 2011), os principais atributos afetados são: teores de $\mathrm{P}$, matéria orgânica (MO), teores de $\mathrm{K}^{+}, \mathrm{Na}^{+}, \mathrm{Ca}^{2+}$ e $\mathrm{Mg}^{2+}$ trocáveis, além da acidez potencial $\left(\mathrm{Al}^{+3}+\mathrm{H}^{+}\right)$, soma se bases $(\mathrm{S})$, capacidade de troca de cátions (CTC), saturação por bases (V\%) e pH do solo.

Alguns trabalhos reportam, na literatura, os efeitos da aplicação de resíduos orgânicos no solo como forma de suplementação nutricional de lavouras e também como descarte seguro. $\mathrm{O}$ aumento de doses de composto aplicadas em solo cultivado com alface se traduziu em aumento linear dos teores de bases trocáveis, P e CTC do solo (Santos et al., 2001). No estudo de Pimentel et al. (2009), os teores de $\mathrm{P}$ e $\mathrm{K}^{+}$trocáveis responderam às doses de compostos orgânicos, independente

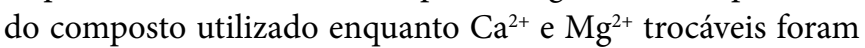
influenciados pela qualidade do composto. Brito et al. (2005) observaram maiores aumentos no teor de $\mathrm{Ca}^{2+}$ trocável, $\mathrm{MO}$ e CTC do solo, quando adubado com esterco ovino e aumento de teores de $\mathrm{P}$ com esterco de poedeiras. Aumentos lineares nos teores de $\mathrm{MO}, \mathrm{Ca}^{2+} \mathrm{e} \mathrm{Mg}^{2+}$ trocáveis, valor $\mathrm{Se}$ CTC do solo foram observados por Cardoso et al. (2011) estudando a aplicação de doses do composto orgânico comercial (Biomix ${ }^{\circ}$ em plantas de alface. Ferraz Júnior et al. (2003) verificaram que a aplicação de lodo de cervejaria na cultura da alface proporcionou aumento no teor de $\mathrm{Mg}^{2+}$ trocável do solo, com efeitos similares àqueles obtidos com esterco de galinha. Os teores no solo de $\mathrm{MO}, \mathrm{P}$ e K ${ }^{+}$ trocável aumentaram com a aplicação de doses de composto à base de cama de aves e dejetos suínos aplicados em alface, porém não houve efeito das mesmas sobre o $\mathrm{pH}$ do solo (Parizotto \& Pandolfo, 2009). Barral et al. (2011) verificaram aumento da disponibilidade de $\mathrm{Ca}^{2+}, \mathrm{Mg}^{2+}$ e $\mathrm{K}^{+}$trocáveis ao aplicar composto produzido com resíduos urbanos em alface. Pimentel et al. (2009), aplicaram na alface composto à base de esterco bovino, capim e restos culturais e observaram máxima disponibilidade de $\mathrm{P}, \mathrm{Ca}^{2+}$ e $\mathrm{Mg}^{2+}$ trocáveis às plantas, aos 6 dias após o plantio. Já Barral et al. (2011) constataram que as concentrações de P disponíveis não foram aumentadas por adição de composto, efeito que foi atribuído tanto à imobilização microbiana como à capacidade de fixação do $\mathrm{P}$ no solo.

A grande maioria dos trabalhos encontrados na literatura se refere ao uso de estercos, resíduos líquidos e restos vegetais, reportando seu efeito em parâmetros de produtividade e nutrição da alface.

São poucos, porém, os trabalhos nos quais foram estudadas as modificações dos atributos químicos do solo em cultivo da alface adubada com compostos orgânicos. O objetivo foi avaliar as alterações das características químicas do solo e a resposta produtiva da alface adubada com compostos orgânicos produzidos artesanalmente a partir de resíduos e/ou matérias primas.

\section{MATERIAL E MÉtodos}

O experimento foi conduzido em casa de vegetação na Universidade Federal Rural de Pernambuco - UFRPE. A terra utilizada no experimento foi proveniente de um Argissolo Vermelho-Amarelo distrófico (EMBRAPA, 2006), coletada na camada superficial do solo (0 a $20 \mathrm{~cm}$ ), no Campus da UFRPE. Amostras de terra (TFSA) foram utilizadas para caracterização química e física (Tabela 1), conforme EMBRAPA (2009).

O experimento foi conduzido em delineamento em blocos casualizados, em esquema fatorial $5 \times 4$, sendo cinco tipos de compostos orgânicos (Tabela 2), cujas características químicas

Tabela 2. Composição e origem dos compostos orgânicos

\begin{tabular}{|c|c|c|}
\hline Compostos & Composição & $\begin{array}{l}\text { Origem dos } \\
\text { compostos }\end{array}$ \\
\hline 1 & $\begin{array}{l}\text { Grama, casca de mandioca e } \\
\text { bagaço de cana-de-acúcar }\end{array}$ & Cruz das Almas-BA \\
\hline 2 & Grama e esterco* $^{*}$ & Cruz das Almas-BA \\
\hline 3 & $\begin{array}{l}\text { Resíduos orgânicos doméstico, } \\
\text { urbano e industrial }^{*}\end{array}$ & Recife-PE \\
\hline 4 & $\begin{array}{l}\text { Composto comercial } \\
\left.\text { (Greenworld }^{\circledR}\right)\end{array}$ & Comercial \\
\hline 5 & $\begin{array}{l}\text { Esterco de gado, folha de caju, } \\
\text { folha de manga, rama de } \\
\text { gliricídia, capim seco, pó de } \\
\text { telha, calcário dolomítico, fósforo } \\
\text { natural, farinha de rocha, farinha } \\
\text { de osso e grãos de feijão* }\end{array}$ & Esperança-PB \\
\hline
\end{tabular}

Tabela 1. Características químicas e físicas do solo utilizado no experimento

\begin{tabular}{|c|c|c|c|c|c|c|c|c|c|}
\hline \multirow{2}{*}{$\begin{array}{c}\mathrm{pH}-\mathrm{H}_{2} \mathrm{O} \\
(1: 2,5)\end{array}$} & $\mathrm{H}^{+}+\mathrm{Al}^{3+}$ & $\mathrm{Al}^{3+}$ & $\mathrm{Ca}^{2+}$ & $\mathrm{Mg}^{2+}$ & $\mathrm{K}^{+}$ & $\mathrm{Na}^{+}$ & \multirow{2}{*}{$\begin{array}{c}P \\
\text { (Mehlich-1) } \\
\mathrm{mg} \mathrm{kg}^{-1}\end{array}$} & \multirow{2}{*}{$\underset{\mathrm{g} \mathrm{dm}}{\mathrm{CO}}$} & \multirow{2}{*}{$\underset{\mathrm{g} \mathrm{kg}}{\mathrm{N}}$} \\
\hline & \multicolumn{6}{|c|}{$\mathrm{kg} \mathrm{dm}^{-3}$} & & & \\
\hline 5,20 & 5,50 & 0,91 & 2,20 & 0,50 & 0,45 & 0,14 & 5,85 & 26,5 & 1,70 \\
\hline V & m & \multirow{2}{*}{$\begin{array}{c}\text { CTC } \\
\mathrm{cmol}_{\mathrm{C}} \mathrm{dm}^{-3}\end{array}$} & & \multirow{2}{*}{$\begin{array}{c}\text { Ds } \\
\mathrm{kg} \mathrm{dm}^{-3}\end{array}$} & \multicolumn{2}{|c|}{ Areia } & Silte & \multicolumn{2}{|c|}{ Argila } \\
\hline \multicolumn{2}{|c|}{$\%$} & & & & \multicolumn{3}{|r|}{$\mathrm{g} \mathrm{kg}^{-1}$} & \\
\hline 78,33 & 21,66 & 4,20 & & 1,33 & & & 70,0 & & \\
\hline
\end{tabular}

CO - Carbono orgânico; V - Saturação por bases; $m$ - Saturação por Al+3; CTC - Capacidade de troca de cátions; Ds - Densidade do solo; LD - Abaixo do limite de detecção do equipamento utilizado 
são descritas na Tabela 3 e três doses que corresponderam a 35, 70 e $140 \mathrm{~kg} \mathrm{ha}^{-1} \mathrm{de} \mathrm{N}$ (Tabela 4), mais a testemunha (Tratamento 1) sem aplicação de composto, com quatro repetições, totalizando 80 unidades experimentais.

Tabela 3. Características químicas dos compostos orgânicos utilizados no experimento

\begin{tabular}{lrrrrr}
\hline & \multicolumn{5}{c}{ Compostos $^{\#}$} \\
\cline { 2 - 6 } $\mathrm{pH}\left(\mathrm{H}_{2} \mathrm{O}\right)$ & $\mathbf{1}$ & $\mathbf{2}$ & $\mathbf{3}$ & $\mathbf{4}$ & \multicolumn{1}{c}{$\mathbf{5}$} \\
$\mathrm{MO}(\%)$ & 5,71 & 7,44 & 7,75 & 2,50 & 8,90 \\
$\mathrm{C} / \mathrm{N}$ & 39,00 & 37,00 & 62,00 & 90,00 & 73,00 \\
$\mathrm{~N}\left(\mathrm{~g} \mathrm{~kg}^{-1}\right)$ & 17,20 & 15,50 & 28,46 & 25,65 & 13,75 \\
$\mathrm{P}\left(\mathrm{g} \mathrm{kg}^{-1}\right)$ & 9,40 & 10,40 & 2,60 & 2,30 & 8,40 \\
$\mathrm{~K}^{+}\left(\mathrm{g} \mathrm{kg}^{-1}\right)$ & 2,90 & 3,40 & 3,00 & 4,10 & 4,30 \\
$\mathrm{Ca}^{2+}\left(\mathrm{g} \mathrm{kg}^{-1}\right)$ & 6,70 & 9,87 & 1,23 & 3,95 & 6,42 \\
$\mathrm{Mg}^{2+}\left(\mathrm{g} \mathrm{kg}^{-1}\right)$ & 4,30 & 6,80 & 13,70 & 8,10 & 15,20 \\
\hline
\end{tabular}

MO - Matéria orgânica; C/N - Relação carbono nitrogênio

\# Para descriminação dos compostos ver Tabela 2

Tabela 4. Quantidade de compostos adicionada nos diferentes tratamentos

\begin{tabular}{cccc}
\hline \multirow{2}{*}{ Compostos $^{\#}$} & \multicolumn{3}{c}{ Quantidade (g vaso $^{-1}$ ) } \\
\cline { 2 - 4 } & Tratamento 2 & Tratamento 3 & Tratamento 4 \\
1 & 23,72 & 47,43 & 94,86 \\
2 & 21,35 & 42,70 & 85,40 \\
3 & 85,73 & 171,46 & 342,92 \\
4 & 95,65 & 191,30 & 382,60 \\
5 & 26,54 & 53,07 & 106,14 \\
\hline
\end{tabular}

Tratamento 2 - 0,22 g de N vaso-1, equivalente a $35 \mathrm{~kg} \mathrm{ha}^{-1} \mathrm{de} \mathrm{N}$; tratamento $3-0,45 \mathrm{~g} \mathrm{vaso}^{-1}$, equivalente a $70 \mathrm{ha}^{-1}$ de $\mathrm{N}$; tratamento $4-0,90 \mathrm{~g}$ vaso $^{-1}$, equivalente a $140 \mathrm{~kg} \mathrm{ha}^{-1}$ de $\mathrm{N}$ \# Para descriminação dos compostos ver Tabela 2

Os compostos orgânicos utilizados apresentavam matéria orgânica quase que totalmente decomposta, ou seja, estabilizada. O cálculo das doses para cada material foi baseado na recomendação de nitrogênio para uma densidade populacional de 157.000 plantas de alface por hectare (Cavalcanti, 1998), que é de $70 \mathrm{~kg} \mathrm{ha}^{-1}$ de $\mathrm{N}$ e, com isto, em função dos teores de $\mathrm{N}$ presente em cada composto, os níveis de $\mathrm{N}$ avaliados corresponderam a $0,35,70$ e $140 \mathrm{~kg} \mathrm{ha}^{-1} \mathrm{de} \mathrm{N}$, ou seja, 0; 0,5; 1 e 2 vezes a recomendação, independente do tipo de composto.

Amostras dos compostos foram secadas ao ar, homogeneizadas e passadas em peneira de $2 \mathrm{~mm}$; posteriormente, determinouse o pH em água $(1: 2,5)$; em seguida, efetuou-se digestão nitroperclórica, na proporção 3:1, para determinação de $\mathrm{P}$ por

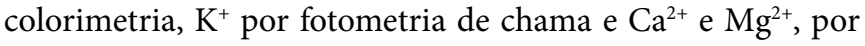
espectrofotometria de absorção atômica e nitrogênio total, este analisado a partir de digestão sulfúrica e determinado de acordo com o método de Kjeldahl, descrito em EMBRAPA (2009); os resultados estão apresentados na Tabela 3.

Para correção da acidez do solo realizou-se a incorporação de carbonato de cálcio e magnésio, sendo que a massa de terra foi mantida em sacos plásticos com umidade em torno de $80 \%$ da capacidade de campo, durante 20 dias período após o qual os solos foram homogeneizados com as doses dos compostos apresentadas na Tabela 4 e depois de 15 dias transferiu-se uma muda de alface para cada um dos vasos.

As mudas de alface cultivar crespa foram cultivadas em bandejas de isopor utilizando-se o substrato comercial
Plantmax, e irrigadas com água destilada durante os primeiros 30 dias, procedendo-se ao transplante para os vasos definitivos, cada um contendo $2,5 \mathrm{~kg}$ de terra. A irrigação foi realizada diariamente com água destilada procurando-se manter $80 \%$ da capacidade de retenção de água mediante pesagem dos vasos para aferição de água perdida por evapotranspiração; após 35 dias a parte aérea das plantas de alface foi coletada e levada à estufa de circulação forçada de ar a $65{ }^{\circ} \mathrm{C}$ durante $48 \mathrm{~h}$ para obtenção da massa seca da parte aérea (MSPA).

Depois da colheita da alface foram retiradas amostras de terra dos vasos para determinação do $\mathrm{pH}, \mathrm{H}^{+}+\mathrm{Al}^{3+}$, Matéria orgânica e os macronutrientes $\left(\mathrm{P}, \mathrm{K}^{+}, \mathrm{Ca}^{2+}\right.$ e $\mathrm{Mg}^{2+}$ trocáveis) conforme EMBRAPA (2009). Com os resultados analíticos foram calculadas a soma de bases (S), a capacidade de troca de cátions (CTC) e a saturação por bases (V\%).

Os dados obtidos foram submetidos à análise de variância, ao teste de Tukey e à análise de regressão utilizando-se o software SISVAR (Ferreira, 2003).

\section{Resultados e Discussão}

A aplicação de doses de nitrogênio no solo na forma de composto afetou a produção de matéria seca da parte aérea nas plantas de alface, independente do tipo de composto orgânico. Nota-se que houve um incremento com ajuste quadrático ( $\mathrm{p}$ $<0,05)$ da produção de matéria seca, atingindo $4,82 \mathrm{~g}$ planta $^{-1}$ com o uso da dose de $111 \mathrm{~kg} \mathrm{ha}^{-1}$ de $\mathrm{N}$, independente do tipo de composto orgânico (Figura 1A). Nota-se, ainda, que o tipo de composto orgânico aplicado no solo afetou a produção de matéria seca da parte aérea, independente da dose aplicada, pois a interação entre dose e tipo de composto não se mostrou significativa pelo teste $F(F=1,56, p=0,14)$; assim, no fator tipo de composto, os compostos 4 (Greenworld') e 2 (Grama e esterco) foram os que apresentaram melhores resultados, 5,13 e 4,24 g planta $^{-1}$ (Figura 1B).

Aumentos da biomassa seca em alface adubada com compostos orgânicos já tinham sido observados por alguns autores (Oliveira et al., 2009; Nazareno et al., 2010; Santana et al., 2012).

Os compostos podem contribuir com o aumento de produção da alface; contudo, o maior ou menor grau de contribuição parece estar ligado ao teor nutricional do composto; neste sentido, o composto 4 pode ter sido o que mais contribuiu para a elevação da produtividade da alface devido à aplicação de maior quantidade em relação aos demais (Tabela 4), já que possuía menores quantidades de nitrogênio (Tabela 3); ainda, a maior quantidade aplicada no solo do composto 4 aliado aos altos teores de matéria orgânica, $900 \mathrm{~g} \mathrm{~kg}^{-1}$ (Tabela 3), em relação aos demais compostos, pode justificar a melhor resposta da planta quanto ao uso deste composto. Por outro lado, a aplicação de menor quantidade do composto 2 (Tabela 4) promoveu o mesmo incremento que o composto $4 \mathrm{em}$ virtude, possivelmente, do valor de $\mathrm{pH}$ mais básico em relação ao composto $4 \mathrm{e}$ maior teor de $\mathrm{K}^{+}$em relação aos outros compostos. 
A.

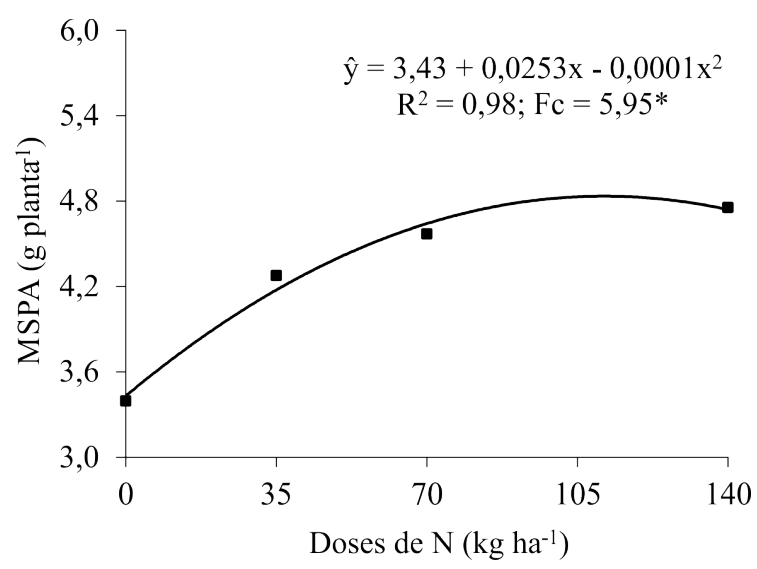

B.

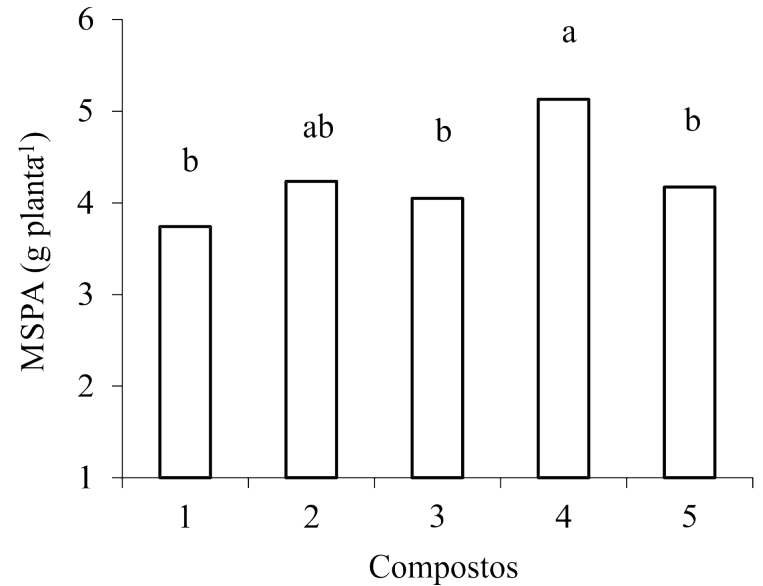

* significante a nível de 0,05 de probabilidade pelo teste $\mathrm{F}$; médias seguidas de mesma letra não diferem pelo teste de Tukey a $p<0,05$

Figura 1. Produção de matéria seca da parte aérea (MSPA) das plantas de alface (A), independente do tipo de composto orgânico usado, em função das doses de $\mathrm{N}$ aplicadas e comparação das médias da MSPA obtida com o uso de cada composto (B)

Oliveira et al. (2009) observaram que o composto de lixo caseiro com restos de cultura e esterco biodigerido foi o que mais proporcionou bioprodução em alface e constataram que o teor nutricional deste composto foi superior aos demais testados.

Além do tipo de composto observou-se, no presente trabalho, que a produção aumentou de forma quadrática em função das doses de compostos; aumentos deste tipo foram observados por Silva et al. (2010) e Santana et al. (2012) em estudo com alface adubada com diferentes doses e compostos orgânicos. Entretanto, ainda existem relatos de falta de resposta produtiva da alface à aplicação de compostos orgânicos (Villas-Bôas et al., 2004; Roel et al., 2007), porém o aumento do valor nutricional da alface adubada com compostos orgânicos em relação à adubação química foi demonstrado por Silva et al. (2011).

Na Tabela 5 são mostrados os efeitos dos tratamentos para os atributos químicos avaliados no solo e seus coeficientes de variação. Os resultados indicam haver interação entre o tipo de composto e as doses avaliadas na maioria das variáveis avaliadas.

Após o desdobramento da interação, através do estudo da regressão polinomial, pôde-se observar que o $\mathrm{pH}$ do solo adubado com os compostos 3 e 5 aumentou, com ajuste quadrático, a elevação da dose atingindo os valores 7,6 e 6,6 com as doses 100 e $167 \mathrm{~kg} \mathrm{ha}^{-1} \mathrm{de} \mathrm{N}$, respectivamente (Figura 2A). De forma notória observou-se que, na maior dose aplicada, o composto 3 elevou o $\mathrm{pH}$ a neutralidade. Alguns trabalhos encontrados na literatura relatam a elevação de $\mathrm{pH}$ em razão da aplicação de adubos orgânicos (Silva et al., 2008; Pimentel et al., 2009). O aumento do $\mathrm{pH}$ é proporcionado pela adsorção de íons $\mathrm{H}^{+}$por ânions dos compostos orgânicos (Mantovani et al., 2005).

Notou-se, no entanto, decréscimo de $\mathrm{pH}$ com a elevação da dose do composto 4. (Figura 2A). $\mathrm{O}$ pH deste composto é muito ácido (Tabela 3); além disto, a mineralização desencadeada pela microbiota do solo, que provoca a nitrificação, pode ter ocasionado decréscimo do $\mathrm{pH}$ (Raij, 2011).

$\mathrm{O}$ composto 1 , apesar de ter $\mathrm{pH}$ ácido, não provocou alteração de $\mathrm{pH}$ do solo. $\mathrm{O}$ composto 2 (esterco mais grama) também não alterou o $\mathrm{pH}$ do solo com o incremento das doses, resultados semelhantes aos observados por Brito et al. (2005) com a aplicação de doses de estercos em um Latossolo.

Sabe-se, pelo menos temporariamente, que a tendência é de que o pH se eleve com a adição de composto orgânico ao solo sobretudo em razão das bases trocáveis, como $\mathrm{Ca}^{2+}, \mathrm{Mg}^{2+}, \mathrm{K}^{+}$ e $\mathrm{Na}^{+}$(Kiehl, 1985). A remoção dessas bases pelas plantas ou pela lixiviação é que provoca a acidificação do solo (Raij, 2011).

A acidez potencial $\left(\mathrm{H}^{+}+\mathrm{Al}^{+3}\right)$ no solo apenas aumentou com a adição do composto 4 atingindo o valor $6,1 \mathrm{com}$ a dose de $113 \mathrm{~kg}$ de N (Figura 2B). Este composto apresentou pH ácido; corroborando com os resultados observados para o $\mathrm{pH}$ do solo notou-se que, de forma geral, o comportamento da acidez potencial foi inversamente proporcional ao comportamento do $\mathrm{pH}$. Isto ocorre em razão da acidez ser a troca de cátions básicos do complexo de troca catiônica por $\mathrm{Al}^{3+}$ trocável e $\mathrm{H}^{+}$ não dissociado (Raij, 2011).

Não se verificou efeito dos compostos 1 e 2 sobre a acidez potencial, o que pode ter sido devido ao valor de $\mathrm{pH}$ em $\mathrm{H}_{2} \mathrm{O}$ no

Tabela 5. Resumo de análise de variância (ANOVA) das propriedades químicas do solo após 35 dias de cultivo com alface sob aplicação de compostos orgânicos

\begin{tabular}{|c|c|c|c|c|c|c|c|c|c|c|c|}
\hline & \multicolumn{11}{|c|}{ Quadrado médio } \\
\hline & $\mathrm{pH}$ & $\mathrm{H}^{+}+\mathrm{Al}^{3+}$ & $S$ & V & CTC & $\mathbf{P}$ & $\mathrm{Ca}^{2+}$ & $\mathrm{Mg}^{2+}$ & $\mathrm{K}^{+}$ & $\mathrm{Na}^{+}$ & MO \\
\hline & \multicolumn{11}{|c|}{ valor F calculado } \\
\hline Compostos & $288,9^{* *}$ & $167,8^{* *}$ & $41,8^{* *}$ & $66,3^{* *}$ & $88,3^{* *}$ & $472,6^{* *}$ & $220,5^{* *}$ & $18,6^{* *}$ & $124,8^{* \star}$ & $31,7^{* *}$ & $3,8^{* *}$ \\
\hline Doses de N & $19,3^{\text {** }}$ & $1,4^{\mathrm{ns}}$ & $35,4^{*}$ & $29,5^{\text {** }}$ & $36,4^{* *}$ & $469,7^{* *}$ & $175,2^{\text {** }}$ & $5,4^{* \star}$ & $192,8^{* *}$ & $151,2^{* *}$ & $13,9^{* \star}$ \\
\hline Interação & $39,5^{* *}$ & $20,4^{\text {**}}$ & $8,7^{\text {** }}$ & $8,6^{* *}$ & $15,6^{* *}$ & $54,8^{* *}$ & $55,7^{\text {** }}$ & 4,6 ** & 36,6 ** & $12,2^{* *}$ & $1,6^{\mathrm{ns}}$ \\
\hline C.V. (\%) & 2,91 & 14,58 & 17,19 & 6,12 & 11,99 & 9,02 & 9,92 & 15,0 & 14,19 & 17,12 & 9,58 \\
\hline
\end{tabular}

$\mathrm{S}$ - soma de bases; $\mathrm{V}$ - saturação por bases; CTC - capacidade de troca de cátions; M0 - matéria orgânica; ns não-significativo, * significativo a $\mathrm{p}<0,05$, ** significativo a $\mathrm{p}<0,01$ 
A.

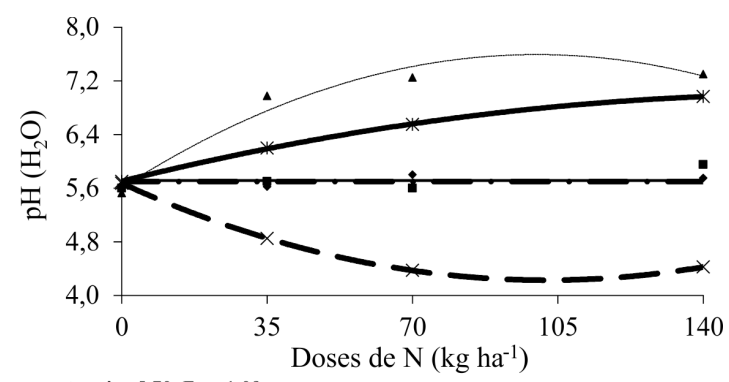

-1 $\hat{\mathrm{y}}=5,70 ; \mathrm{Fc}=1,09^{\mathrm{ns}}$

- $2 \hat{\mathrm{y}}=5,71 ; \mathrm{Fc}=3,76^{\mathrm{ns}}$

$\triangle 3 \hat{y}=5,61+0,0398 x-0,0002 x^{2} ; R^{2}=0,96 ; F c=102,87 * *$

-... $\times 4 \quad \hat{y}=5,67-0,0283 x+0,0001 x^{2} ; R^{2}=1 ; F c=49,64 * *$

B.

- $* 5 \quad \hat{y}=5,71+0,01546-5 \mathrm{E}-05 \times 2 ; \mathrm{R}=0,99 ; \mathrm{F}=13,78^{* *}$

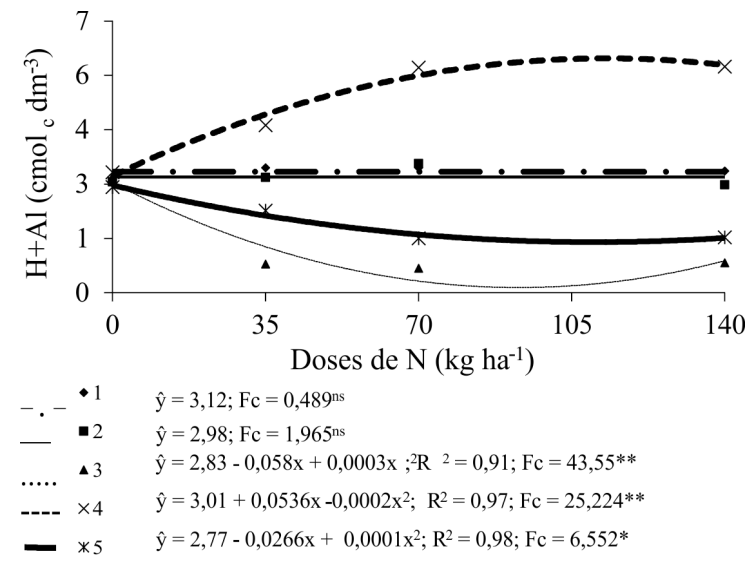

$\mathrm{Fc}$ - Valor $\mathrm{F}$ calculado; ns não significante, * significante a $\mathrm{p}<0,05,{ }^{* *}$ significante a $\mathrm{p}<0,01$

Figura 2. Valores de $\mathrm{pH}(\mathrm{A})$ e teores de $\mathrm{H}^{+}+\mathrm{Al}^{+3}$ (B) no solo cultivado por 35 dias com alface, após aplicação de compostos orgânicos

solo estar próximo de 5,6, valor este em que o $\mathrm{Al}^{3+}$ se encontra precipitado (Raij, 2011) e, portanto, não trocável. Ressalta-se que, mesmo o composto 2 apresentando um pH de 7,44 (Tabela 3), a quantidade aplicada no solo não foi suficiente para elevar o pH do solo, apresentando média de 5,7 (Figura 2A).

A soma de bases (S) aumentou com ajuste linear no solo adubado com os compostos 3 e 4, a qual atingiu 11,11 e 16,47, respectivamente, com o uso da dose de $140 \mathrm{~kg} \mathrm{ha}^{-1}$ de N (Figura $3 \mathrm{~A})$. Esses compostos apresentavam menor quantidade de $\mathrm{N}$ (Tabela 3); portando; foram aplicados em quantidades maiores ao solo em relação aos demais (Tabela 4) razão pela qual se constituíram as maiores somas de bases. Santos et al. (2001) também verificaram aumento da soma de bases ao aplicar adubos orgânicos ao solo.

Já a saturação por bases (V\%) aumentou de forma quadrática com o uso dos compostos 3 e 5 atingindo os valores 101 e 83 com as doses 96 e $113 \mathrm{~kg} \mathrm{ha}^{-1}$ de $\mathrm{N}$, respectivamente (Figura 3B). Nos compostos 2 e 4 o aumento começou a ocorrer com a adição da dose de $70 \mathrm{~kg}$ de $\mathrm{N}$ sendo bem menos pronunciado.

A saturação por bases expressa parte da CTC ocupada pela soma de bases no complexo de troca catiônica (Raij, 2011); previa-se, então, uma relação de seus valores com o $\mathrm{pH}$ do solo, o que foi observado (Figura 2A). Cardoso et al. (2011) constataram aumento, tanto da soma de bases como da
A.

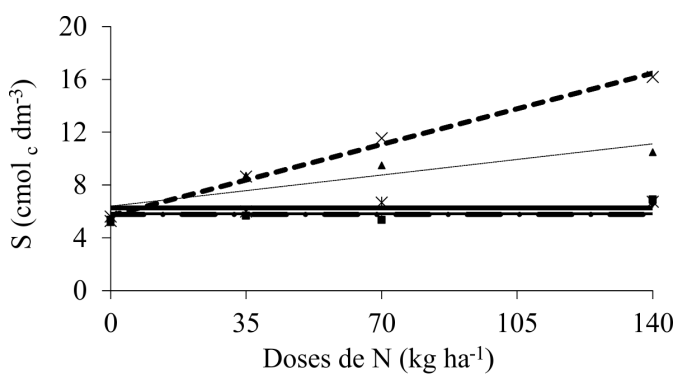

B.

$$
\begin{array}{lll}
-.- & \bullet 1 & \hat{y}=5,77 ; F c=0,884^{\text {ns }} \\
- & \bullet 2 & \hat{y}=5,81, F c=1,377^{\text {ns }} \\
\ldots . . & \bullet 3 & \hat{y}=6,38+0,0338 x ; R^{2}=0,77 ; F c=7,892 * * \\
--- & \times 4 & \hat{y}=5,68+0,0771 x ; R^{2}=0,99 ; F c=160,024^{* *} \\
-\quad & * 5 & \hat{y}=6,26 ; F c=0,752^{\text {ns }}
\end{array}
$$

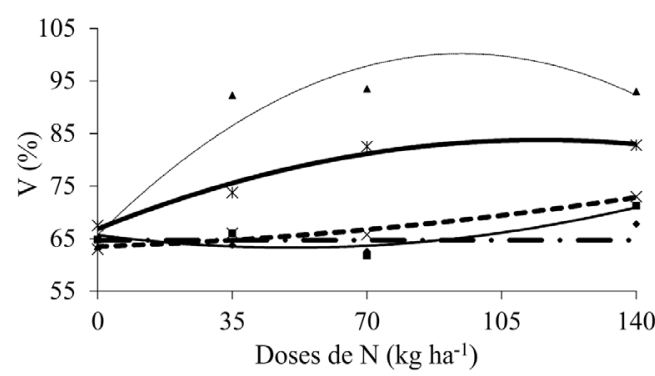

$-.-\cdot 1 \quad \hat{\mathrm{y}}=64,69 ; \mathrm{Fc}=1,065^{\mathrm{ns}}$

- $2 \hat{\mathrm{y}}=65,69-0,0963 \mathrm{x}-0,001 \mathrm{x}^{2} ; \mathrm{R}^{2}=0,77 ; \mathrm{Fc}=3,948^{*}$

.... $\triangle 3 \hat{y}=65,67+0,729 x-0,0038 x^{2} ; R^{2}=0,91 ; F c=57,709^{* *}$

---- $\times 4 \quad \hat{y}=63,48+0,0253 x+0,0003 x^{2} ; R^{2}=0,95 ; F c=10,341^{* *}$

- $* 5 \quad \hat{y}=66,82+0,2939 x-0,0013 x^{2} ; R^{2}=0,97 ; F c=6,335^{*}$

$\mathrm{Fc}$ - Valor F calculado; ns não significante, ${ }^{*}$ significante a $\mathrm{p}<0,05,{ }^{* *}$ significante a $\mathrm{p}<0,01$

Figura 3. Soma de bases (A) e saturação por bases

(B) do solo cultivado por 35 dias com alface, após aplicação de compostos orgânicos

saturação por bases, aplicando compostos orgânicos em solo cultivado com alface.

Todos os compostos provocaram aumento no teor de $\mathrm{P}$ em função das doses, ou seja, todos tenderam a aumentar os teores desse nutriente no solo (Figura 4B). Segundo os limites de interpretação de teores de $\mathrm{P}$ disponível no solo, estabelecidos para a cultura da alface no estado de Pernambuco, o teor de $\mathrm{P}$ no solo passou da classe baixo $\left(5,85 \mathrm{mg} \mathrm{kg}^{-1}\right)$ para médio, nos tratamentos $1\left(20,68 \mathrm{mg} \mathrm{kg}^{-1}\right)$ e $2\left(24,06 \mathrm{mg} \mathrm{kg}^{-1}\right)$ e nos demais tratamentos está acima de $30 \mathrm{mg} \mathrm{kg}^{-1}$, teores considerados altos (Figura 4B). O aumento de P com a aplicação de adubos orgânicos foi observado anteriormente (Santos et al., 2001; Brito et al., 2005); porém Barral et al. (2011) não obtiveram aumento de $\mathrm{P}$ em solo adubado com composto de lixo urbano, o que atribuíram à imobilização microbiana e à capacidade de fixação do P no solo.

Em função das doses, o aumento da CTC foi significativo para o composto 3 apresentando comportamento linear e para o composto 4, apresentando efeito quadrático (Figura 4A). Vários estudos têm constatado aumentos da CTC em função da aplicação de adubos orgânicos (Santos et al., 2001; Brito et al., 2005; Parizotto \& Pandolfo, 2009; Cardoso et al., 2011); sabe-se, entretanto, que a CTC é uma característica inalterável a curto prazo em condições de campo podendo alterar apenas a 
A.

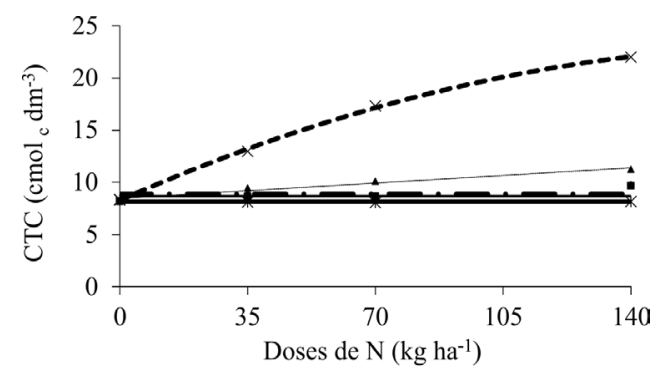

B.

$$
\begin{aligned}
& \text {-.- } \quad \text { •1 } \hat{y}=8,89 ; \mathrm{Fc}=1,104^{\mathrm{nc}} \\
& \text { - } 2 \hat{y}=8,70 ; \mathrm{Fc}=1,049^{\text {ns }} \\
& \text { … } \triangle 3 \hat{y}=8,45+0,0211 \mathrm{x} ; \mathrm{R}^{2}=0,96 ; \mathrm{Fc}=12,827 * * \\
& \text {--- } \quad \times 4 \hat{y}=8,28+0,155 x-0,0004 x^{2} ; R^{2}=1 ; F c=8,337 * *
\end{aligned}
$$

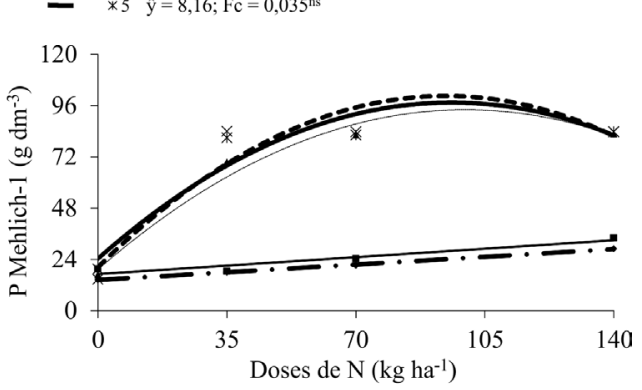

$$
\begin{aligned}
& \text {-. - . } 1 \quad \hat{\mathrm{y}}=14,35+0,1035 \mathrm{x} ; \mathrm{R}^{2}=1 ; \mathrm{Fc}=24,32^{\text {*** }} \\
& \text { - } 2 \hat{\mathrm{y}}=17,15+0,1129 \mathrm{x} ; \mathrm{R}^{2}=0,91 ; \mathrm{Fc}=28,934 * * \\
& \text { …. } A^{3} \quad \hat{y}=14,34+1,4987 x-0,0075 x^{2} ; R^{2}=0,97 ; F_{c}=225,73^{*} \\
& -+-\quad \times 4 \quad \hat{y}=20,45+1,6957 x-0,009 x^{2} \cdot R^{2}=0,88 \cdot F c=322,38^{*} * \\
& \text { - } * 5 \quad \hat{y}=24,40+1,5207 x-0,0079 x^{2} ; R^{2}=0,90 ; F c=250,628^{*}
\end{aligned}
$$

$\mathrm{Fc}$ - Valor $\mathrm{F}$ calculado; ${ }^{\text {ns }}$ não significante, ** significante a $\mathrm{p}<0,01$

Figura 4. Capacidade de troca de cátions $(\mathrm{A})$ e teores de P (B) no solo cultivado por 35 dias com alface após aplicação de compostos orgânicos

proporção relativa dos cátions que ocupam a CTC (Raij, 2011). Talvez o aumento esteja ligado à menor perda por mineralização da matéria orgânica já que o experimento foi conduzido em condições controladas.

Para o $\mathrm{Ca}^{2+}$ trocável o composto 3 apresentou comportamento linear e o composto 4 um comportamento quadrático (Figura 5A) enquanto para $\mathrm{Mg}^{2+}$ em ambos os compostos (3 e 4) o comportamento foi quadrático (Figura 5B). Os teores de $\mathrm{Ca}^{2+}$, após a aplicação desses compostos foram elevados no solo enquanto que os de $\mathrm{Mg}^{2+}$ tenderam a diminuir com a aplicação do composto 3. Esta tendência de redução dos teores de $\mathrm{Mg}^{+2}$ parece estar ligada aos maiores valores de $\mathrm{pH}(7,75)$ presentes no composto 3 , enquanto que o composto 4 apresentava menores valores de $\mathrm{pH}(2,5)$ (Tabela 3$)$. Alguns autores também observaram aumento nos teores de $\mathrm{Mg}^{2+} \mathrm{e} \mathrm{Ca}^{2+}$ (Barral et al., 2011; Cardoso et al., 2011) mesmo que Ferraz Júnior et al. (2003) e Silva et al. (2008) tenham observado aumentos apenas nos teores de $\mathrm{Mg}^{2+}$ enquanto Brito et al. (2005) constataram aumento de $\mathrm{Ca}^{2+}$.

Os teores de $\mathrm{K}^{+}$no solo apresentaram aumento linear atingindo 0,$33 ; 0,52 \mathrm{e} 0,30 \mathrm{cmol}_{\mathrm{c}} \mathrm{dm}^{-3}$ para os compostos $1,2 \mathrm{e}$ 4 até a dose de $140 \mathrm{~kg} \mathrm{ha}^{-1}$ respectivamente (Figura 6A). Barral et al. (2011) constataram aumento no teor de $\mathrm{K}^{+}$no solo com o aumento das doses de composto de lixo urbano. $\mathrm{O}$ composto 2 , que apresentou o maior teor de $\mathrm{K}^{+}$dentre os compostos estudados, elevou em cinco vezes o $\mathrm{K}^{+}$do solo com a maior dose aplicada. Parizotto \& Pandolfo (2009) também observaram
A.

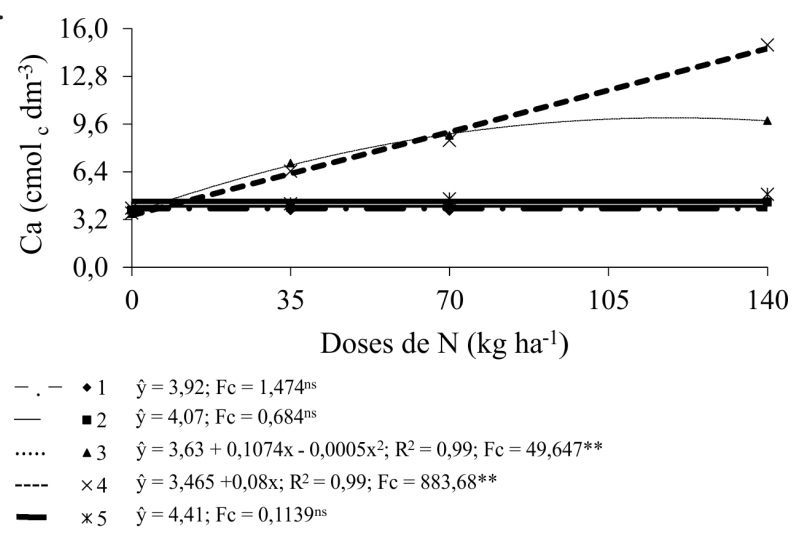

B.

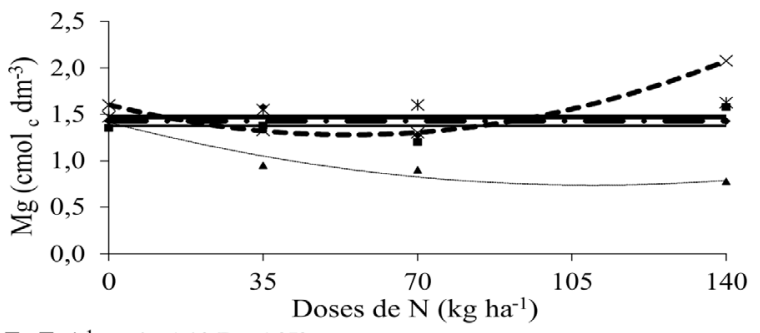

$-,-\cdot 1 \quad \hat{\mathrm{y}}=1,46 ; \mathrm{Fc}=1,372^{\mathrm{ns}}$

- 2 y $=1,38 ; \mathrm{Fc}=2,172^{\text {ns }}$

$\cdots . \Delta \hat{\mathrm{y}}=1,41-0,0123 \mathrm{x}+6 \mathrm{E}-05 \mathrm{x}^{2} ; \mathrm{R}^{2}=0,93 ; \mathrm{Fc}=5,434$

$-\ldots 4 \quad \hat{y}=1,60-0,0119 x+0,0001 x^{2} ; R^{2}=1 ; F c=20,497$ *

- $* 5 \hat{\mathrm{y}}=1,47 ; \mathrm{Fc}=0,400^{\mathrm{ns}}$

$\mathrm{Fc}$ - Valor F calculado; ${ }^{\text {ns }}$ não significante, * significante a $\mathrm{p}<0,05$, ** significante a $\mathrm{p}<0,01$

Figura 5. Teores de $\mathrm{Ca}^{+2}(\mathrm{~A})$ e $\mathrm{Mg}^{+2}$ (B) no solo cultivado por 35 dias com alface, após aplicação de compostos orgânicos

A.

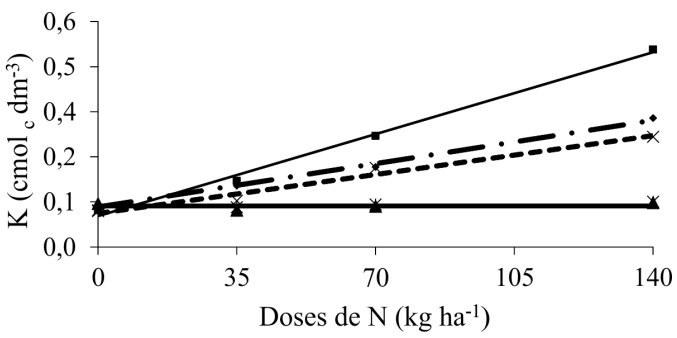

_ $1 \quad \hat{y}=0,1065+0,0016 x ; R^{2}=0,99 ; F c=187,43 * *$

- $2 \hat{y}=0,0825+0,0031 x ; R^{2}=0,99 ; F c=2,558^{* *}$

… $\Delta 3 \quad \hat{\mathrm{y}}=0,11 ; \mathrm{Fc}=0,519^{\text {ns }}$

$---\quad \times 4 \quad \hat{y}=0,0895+0,0015 x ; R^{2}=0,97 ; F c=150,48^{* *}$

B.

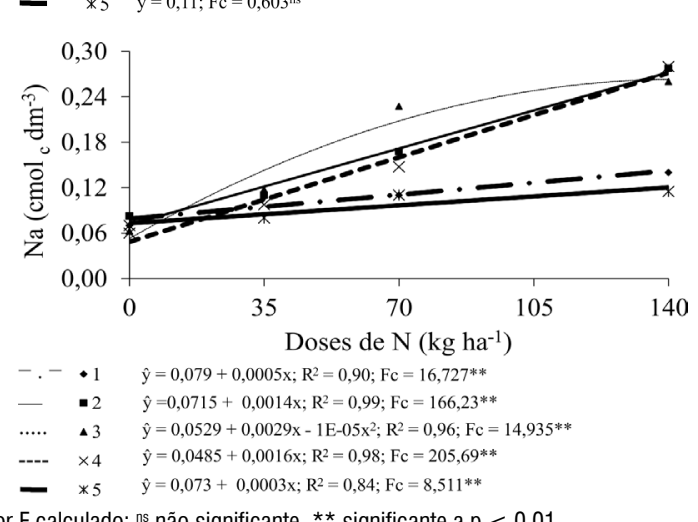

$\mathrm{FC}$ - Valor $\mathrm{F}$ calculado; ns não significante, ** significante a $\mathrm{p}<0,01$

Figura 6. Teores de $\mathrm{K}^{+}$(A) e $\mathrm{Na}^{+}$(B) no solo cultivado por 35 dias com alface, após aplicação de compostos orgânicos 
aumento do $\mathrm{K}^{+}$em solo cultivado com alface adubada com composto produzido de dejetos suínos.

Todos os compostos, com exceção do 3 , que causou aumento quadrático com $0,26 \mathrm{cmol}_{\mathrm{c}} \mathrm{dm}^{-3}$ na dose de $143 \mathrm{~kg} \mathrm{ha}^{-1} \mathrm{de} \mathrm{N}$, proporcionaram aumento linear no teor de $\mathrm{Na}^{+}$no solo sendo que os pontos de máximas observados para os compostos 1 , 2 , 4 e 5 foram 0,$15 ; 0,27 ; 0,27$ e 0,12 com $140 \mathrm{~kg} \mathrm{ha}^{-1}$ de N, respectivamente (Figura 6B) em que o 2, 3 e 4 ocasionaram aumentos de até cinco vezes dos teores deste elemento no solo nas doses mais elevadas sugerindo que o uso continuado de compostos talvez possa ocasionar acúmulo de sódio trocável no solo. $\mathrm{O} \mathrm{Na}^{+}$em excesso pode ocasionar aumento de salinidade exercendo efeito prejudicial às plantas de alface (Paullus et al., 2010).

A matéria orgânica do solo foi influenciada pelos fatores em estudo, isoladamente. De maneira geral, as doses aumentam a MO do solo, independente do tipo de composto, até 23,05 g $\mathrm{dm}^{-3}$ com o uso da dose de $140 \mathrm{~kg} \mathrm{ha}^{-1}$ (Figura 7A). Parizotto \& Pandolfo (2009) e Cardoso et al. (2011) também observaram aumento linear da $\mathrm{MO}$ com doses de compostos orgânicos em alface.

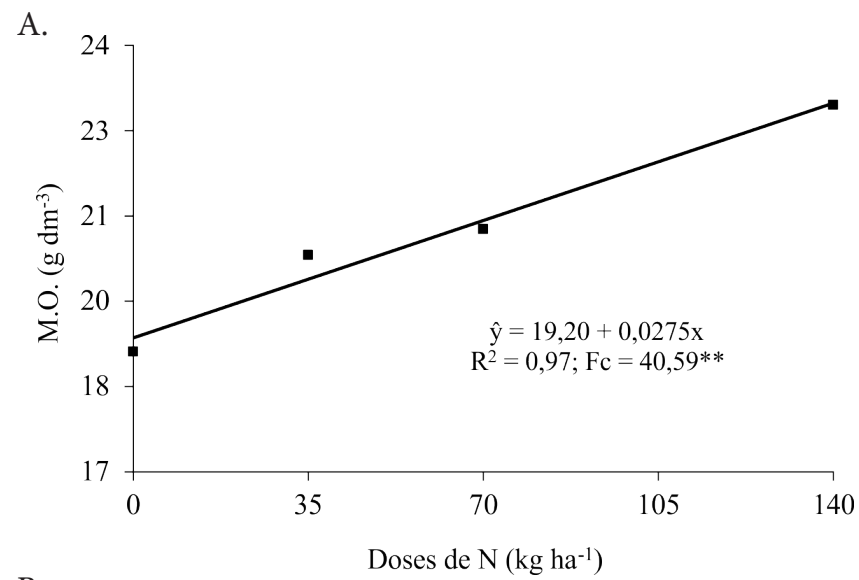

B.

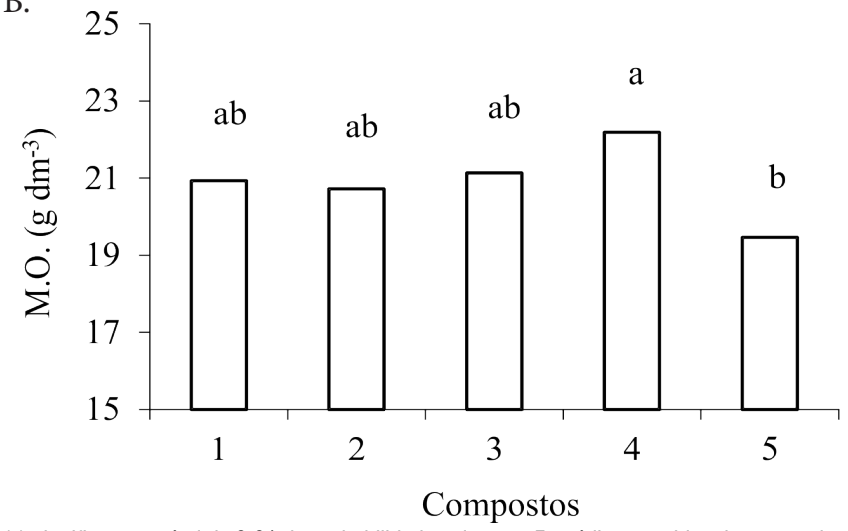

** significante a nível de 0,01 de probabilidade pelo teste F; médias seguidas de mesma letra não diferem pelo teste de Tukey a $p<0,05$

Figura 7. Teores de matéria orgânica no solo cultivado com alface por 35 dias em função das doses de $\mathrm{N}$ aplicadas, independente do tipo de composto orgânico aplicado (A) e comparação das médias da $\mathrm{MO}$ do solo com o uso de cada composto (B)
Notou-se diferença significativa pelo teste $\mathrm{F}$ a 0,05 de probabilidade, do teor de matéria orgânica do tratamento com o composto 3 em relação ao 5 sendo que o teor de $\mathrm{MO}$ foi $12,3 \%$ a mais que o 5 (Figura 7B). Brito et al. (2005) reportam diferenças no teor de $\mathrm{MO}$ do solo adubado com diferentes resíduos orgânicos.

Com exceção do tratamento 4, os teores de $\mathrm{MO}$ dos compostos (Tabela 3) estão próximos do valor mínimo de 300 $\mathrm{g} \mathrm{kg}^{-1}$, indicado por Kiehl (1985) para compostos orgânicos; apesar disto, este tratamento foi o que apresentou melhores resultados significativos no fornecimento de $\mathrm{MO}$ ao solo (Figura 7B).

\section{Conclusões}

1. De maneira geral, os compostos estudados proporcionam aumento de produção de matéria seca da alface e da matéria orgânica no solo sendo que as maiores contribuições são atribuídas ao uso do composto 4 (Greenworld").

2. A elevação de doses dos compostos orgânicos favorece, por ocasião da adubação da alface, o aumento dos teores de fósforo e sódio trocável no solo.

3. Os compostos 3 (resíduos orgânicos doméstico, urbano e industrial) e 5 (esterco de gado, folha de caju, folha de manga, rama de gliricídia, capim seco, pó de telha, calcário dolomítico, fósforo natural, farinha de rocha, farinha de osso e grãos de feijão) aumentam os teores de $\mathrm{Ca}^{2+}$ no solo.

4. O teor de potássio trocável no solo só não é aumentado com o uso do composto 3 (resíduos orgânicos doméstico, urbano e industrial).

5. Os compostos 3 (resíduos orgânicos doméstico, urbano e industrial) e 4 (composto comercial - Greenworld) melhoram principalmente as características químicas do solo $(\mathrm{pH}$, soma de bases, capacidade de troca catiônica e saturação por bases) e reduzem a acidez potencial.

\section{Literatura Citada}

Abreu Júnior, C. H.; Muraoka, T.; Oliveira, F. C. Carbono, nitrogênio, fósforo e enxofre em solos tratados com composto de lixo urbano. Revista Brasileira de Ciência do Solo, v.26, p.769-780, 2002.

Barral, M. T.; Paradelo, R.; Dominguez, M.; Díaz-Fierros, F. Nutrient release dynamics in soils amended with municipal solid waste compost in laboratory incubations. Compost Science \& Utilization, v.19, p.235-243, 2011.

Brito, O. R.; Vendrame, P. R. S.; Brito, R. M. Alterações das propriedades químicas de um Latossolo Vermelho distroférrico submetido a tratamentos com resíduos orgânicos. Semina: Ciências Agrárias, v.26, p.33-40, 2005.

Cardoso, A. I. I.; Ferreira, K. P.; Vieira Júnior, R. M.; Alcarde, C. Alterações em propriedades do solo adubado com composto orgânico e efeito na qualidade das sementes de alface. Horticultura Brasileira, v.29, p.594-599, 2011. 
Cavalcanti, F. J. A. Recomendação de adubação para o Estado de Pernambuco. 2.ed. 2a a aproximação. Recife: IPA, 1998. 198p.

Cunha, E. Q.; Stone, L. F.; Ferreira, E. P. B.; Didonet, A. D.; Moreira J. A. A. Atributos físicos, químicos e biológicos de solo sob produção orgânica impactados por sistemas de cultivo. Revista Brasileira de Engenharia Agrícola e Ambiental, v.16, p.56-63, 2012.

EMBRAPA - Empresa Brasileira de Pesquisa Agropecuária Centro Sistema brasileiro de classificação de solos. 2.ed., Rio de Janeiro: CNPS, 2006. 306p.

EMBRAPA - Empresa Brasileira de Pesquisa Agropecuária Manual de análises químicas de solos, plantas e fertilizantes. Brasília: Embrapa Informação Tecnológica, 2009. 627p.

Ferraz Júnior, L. S. A.; Souza, R. S.; Castro, P. R. S.; Perreira. B. R. Produção de alface com doses de lodo de esgoto. Horticultura Brasileira, v.21, p.60-63, 2003.

Ferreira, D. F. Sisvar Versão 4.6 (Build 6.1). DEX/UFLA. 2003. http://www.dex.ufla.br/index.php?option=com_ content\&task=view\&id=64\&Itemid=1. 21 Out. 2013.

Figueiredo, P. G.; Tanamati, F. Y. Adubação orgânica e contaminação ambiental. Revista Verde de Agroecologia e Desenvolvimento Sustentável, v.5, p.1-4, 2010.

Galbiatti, J. A.; Cavalcante, I. H. L; Ribeiro, A. G.; BeckmannCavalcante, M. Z. Fertilização e qualidade da água de irrigação no crescimento e desenvolvimento da alface. Scientia Agraria, v.8, p.185-192, 2007.

Kiehl, E. J. Fertilizantes Orgânicos. São Paulo: Ceres, 1985. 492p.

Mantovani, J. R.; Ferreira, M. E.; Cruz, M. C. P. Produção de alface e acúmulo de nitrato em função da adubação nitrogenada. Horticultura Brasileira, v.23, p.758-762, 2005.

Montemurro, F.; Ferri, D.; Tittarelli, F.; Canali', S.; Vitti, C. Anaerobic digestate and on-farm compost application: Effects on lettuce (Lactuca sativa L.) crop production and soil properties. Compost Science \& Utilization, v.18, p.184193, 2010.

Nazareno, G. G.; Junqueira, A. M. R.; Peixoto, J. R. Utilização de matéria orgânica para o controle de nematóides das galhas em alface sob cultivo protegido. Bioscience Journal, v.26, p.579-590, 2010.

Oliveira, E. M.; Queiroz, S. B.; Silva, V. F. Influência da matéria orgânica sobre a cultura da alface. Engenharia Ambiental, v.6, p.285-292, 2009.

Oliveira, E. Q.; Souza, R. J.; Cruz, M. C. M.; Marques, V. B.; França, A. C. Produtividade de alface e rúcula, em sistema consorciado, sob adubação orgânica e mineral. Horticultura Brasileira, v.28, p.36-40, 2010.
Parizotto, C.; Pandolfo, C. M. Produção orgânica de alface e atributos de solo pela aplicação de composto de dejetos de suínos. Revista Brasileira de Agroecologia, v.4, p.195-199, 2009.

Paullus, D.; Dourado Neto D.; Frizzone J. A.; Soares, T. M. Produção e indicadores fisiológicos de alface sob hidroponia com água salina. Horticultura Brasileira, v.28, p.29-35, 2010.

Pimentel, M. S.; De-Polli, H.; Lana, Â. M. Q. Atributos químicos do solo utilizando composto orgânico em consórcio de alface-cenoura. Pesquisa Agropecuária Tropical, v.39, p.225-232, 2009.

Raij, B. van. Fertilidade do solo e manejo de nutrientes. Piracicaba: International Plant Nutrition Institute, 2011. 420p.

Resende, F. V.; Saminêz, T. C. O.; Vidal, M. C.; Souza, R. B.; Clemente, F. M. V. Cultivo de alface em sistema orgânico de produção. Brasília: Embrapa Hortaliça, 2007. 16p. Circular técnica, 56

Roel, A. R.; Leonel, L. A. K.; Favaro, S. P.; Zatarim, M.; Momesso, C. M. V.; Soares, M. V. Avaliação de fertilizantes orgânicos na produção de alface em Campo Grande, MS. Scientia Agraria, v.8, p.325-329, 2007.

Santana, C. T. C.; Santi, A.; Dallacort, R.; Santos, M. L.; Menezes, C. B. Desempenho de cultivares de alface americana em resposta na diferentes doses de torta de filtro. Revista Ciência Agronômica, v.43, p.22-29, 2012.

Santos, R. H. S.; Silva, F.; Casali, V. W. D.; Conde, A. R. Efeito residual da adubação com composto orgânico sobre o crescimento e produção de alface. Pesquisa Agropecuária Brasileira, v.36, p.1395-1398, 2001.

Silva, E. M. N. C. P.; Ferreira, R. L. F.; Araújo Neto, S. E.; Tavella, L. B.; Solino, A. J. S. Qualidade de alface crespa cultivada em sistema orgânico, convencional e hidropônico. Horticultura Brasileira, v.29, p.242-245, 2011.

Silva, F. A. M; Villas Bôas, R. L.; Silva, R. B. Resposta da alface à adubação nitrogenada com diferentes compostos orgânicos em dois ciclos sucessivos. Acta Scientiarum. Agronomy, v.32, p.131-137, 2010.

Silva, J. C. P. M.; Motta, A. C. V.; Pauletti; V., Favaretto, N.; Barcellos, M.; Oliveira, A. S.; Veloso, C. M.; Silva, L. F. C. Esterco líquido de bovinos leiteiros combinado com adubação mineral sobre atributos químicos de um Latossolo Bruno. Revista Brasileira de Ciência do Solo, v.3, p.2563-2572, 2008.

Villas Bôas, R. L.; Passos, J. C.; Fernandes, M.; Büll, L. T.; Cezar, V. R. S.; Goto, R. Efeito de doses e tipos de compostos orgânicos na produção de alface em dois solos sob ambiente protegido. Horticultura Brasileira, v.22, p.28-34, 2004. 